\title{
Studi Kelayakan Bisnis Usaha Batik Dengan Metode Finansial (Studi Kasus Batik New Collet Desa Jatipelem Kecamatan Diwek Kabupaten Jombang)
}

\author{
Siti Nur Qomariyah¹, Candra Fatmawati Firdaus²
}

1 Universitas KH. Abdul Wahab Hasbullah

2 Universitas KH. Abdul Wahab Hasbullah

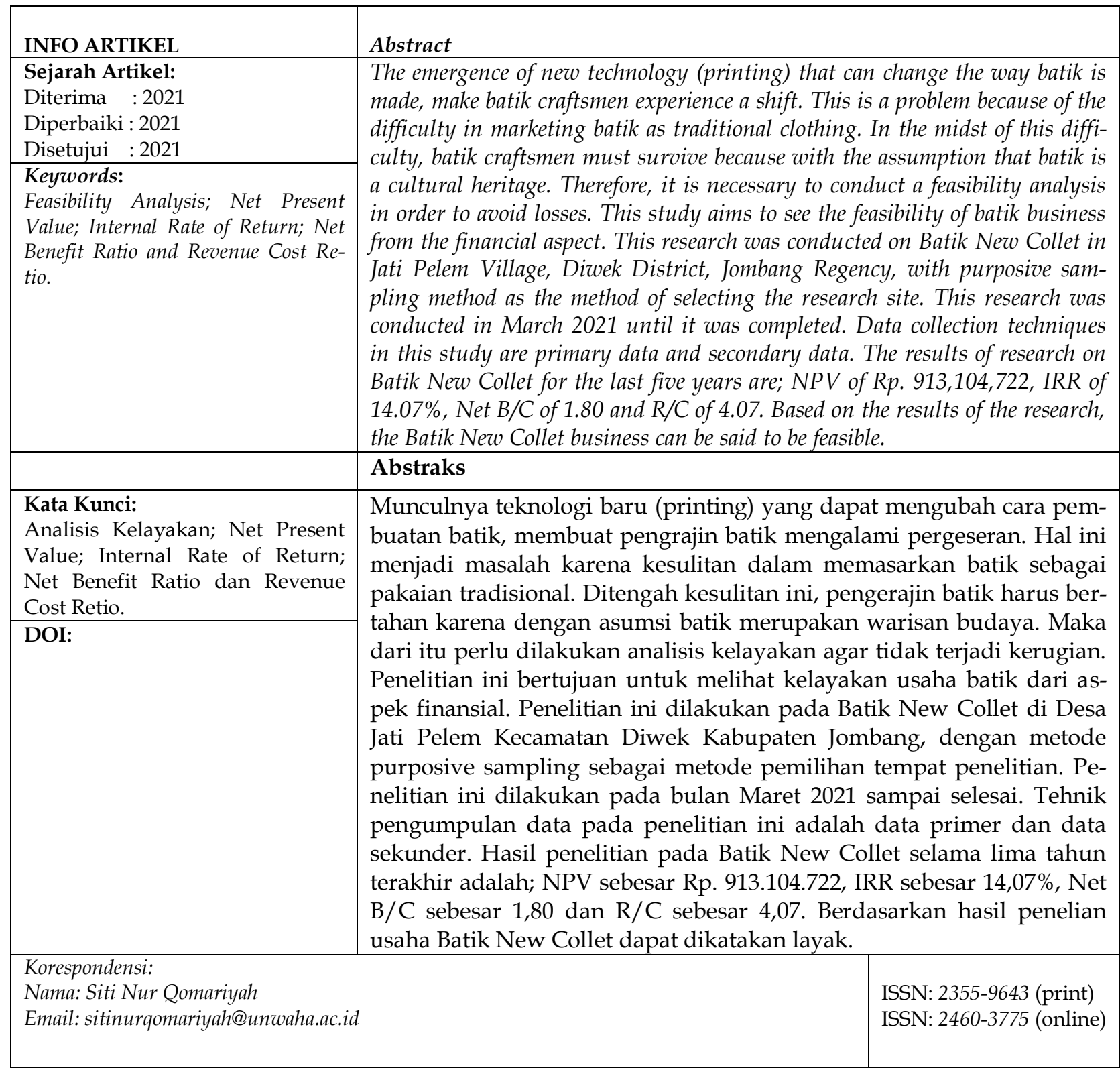




\section{PENDAHULUAN}

Negara Indonesia merupakan negara yang menjunjung tinggi nilai kebudayaan, seiring bertambahnya waktu dan adanya pasar bebas membuat keberadaan budaya di Indonesia tergeser. Dan ini menjadi tantangan bagi Indonesia bahwa kelangkaan mulai menggerogoti budaya. Persaingan dipasar global membuat negara Indonesia lebih mudah tergeser akan budayanya karena teknologi dan juga informasi yang semakin cepat dan mudah untuk diketahui. Pengenalan budaya di negara negara asing sangat bagus dan mendorong betapa kayanya Indonesia terhadap budaya yang dimiliki, akan tetapi pengenalan budaya tersebut jika tidak di imbangi dengan pertahanan budaya bisa terjadi pengeclaim-an terhadap budaya tersebuat. Untuk itu negara Indonesia juga memerlukan strategi yang tepat untuk mempertahankan budaya di Indonesia dan juga pemasaran yang tepat. Salah satunya adalah budaya berpakaian, batik merupakan pakaian adat yang berasal dari adat Jawa. Di kota Jombang, batik berkembang ditahun 2000 an, sehingga tantangan untuk mengembangkan dan mempertahankan semakin berat.

Batik Jombang saat ini dikembangkan oleh beberapa UMKM. UMKM merupakan usaha mikro, usaha kecil dan usaha menengah yang dijalankan oleh individu atau kelompok yang masing masing memiliki kriteria sendiri sebagai pembeda, baik secara modal usaha dan juga pendapatan yang diterima setiap tahunnya. Karena usaha ini merupakan usaha yang terbilang kecil, maka perlu adanya perkembangan dalam pelaporan keuangan, agar investor dan bantuan dari pemerintah maupun pinjaman modal perbankan dapat dilakukan. Sejauh ini kendala yang sering terjadi pada UMKM adalah kurangnya pengetahuan terhadap laporan keuangan, yang mana hal ini menghambat pihak eksternal kurang mempercayai dalam hal finansial terutama pinjaman modal. Salah satu UMKM di Jombang terutama di Desa Jati pelem Kecamatan Diwek ini mengembangkan dan melestarikan batik Jombang adalah Batik New Colet. Usaha yang sudah mulai banyak dikunjungi oleh beberapa wisata asing dan juga telah banyak melakukan kerjasama dengan beberapa lembaga pendidikan.

Masalah yang dihadapi oleh Batik New Colet saat ini adalah adanya pemain baru berupa mesin masin yang dapat mencetak motif batik lebih cepat daripada Batik itu sendiri. Hal ini membuat kekhawatiran pengerajin batik, terutama batik yang baru berkembang ditahun 2000 an, untuk produksi dalam skala besar Batik New Colet masih tidak berani, sehingga saat ini produksi batik hanya dilakukan untuk memenuhi pesanan dan tidak banyak persediaan. Demi mengatasi hal tersebut perlu adanya peninjauan atau penilaian kelayakan usaha untuk melihat apakah usaha ini dapat dilanjutkan ditengah tengah produksi batik dengan menggunakan mesin.

Studi kelayakan usaha adalah suatu kegiatan untuk menentukan layak atau tidak usaha tersebut dijalankan dengan mempelajari secara mendalam usaha atau bisnis yang sedang dijalankan (Kasmir \& Jakfar, 2020). Pengertian selanjutnya study kelayakan (Feasibility study) adalah kegiatan yang dalam praktiknya menelaah suatu usulan proyek atau gagasan usaha agar usaha yang dijalankan berjalan dan berkembang sesuai dengan tujuan dan target (Sobana, 2018). Adapun usulan proyek usaha disebut dengan subjeck matters atau objek, usulan proyek ini akan diteliti, diselidiki dan juga dikaji dari berbagai aspek, apakah usaha tersebut memenuhi syarat atau tidak. Aspek aspek yang akan diteliti, dikaji, bahkan diselidiki ini meliputi aspek pemasaran, aspek ekonomi, aspek sosial budaya, aspek yuridis, aspek pedagogis, aspek tehnik, aspek proses input dan output dan aspek komersial (Sobana, 2018).

Sederhanya kelayakan bisnis merupakan penelitian tentang suatu usaha dapat atau tidak berhasil jika dilaksanakan. Studi kelayakan merupakan bentuk penelitian terhadap ide bisnis untuk direalisasikan jika layak dan tidak direalisasikan jika tidak layak. (Nurul \& Warana, 2017). Sedangkan menurut Ibrahim dalam (Khamaludin et al., 2019) studi kelayakan adalah pelaksanaan suatu kegiatan usaha yang mendatangkan seberapa jauh nilai dan manfaat yang diberikan.

Sebelum pelaksanaan studi kelayakan menentukan aspek apa saja yang akan diteliti merupakan kegiatan pertama, hal ini dimaksudkan untuk menentukan apakah proyek tersebut layak atau tidak layak untuk dilaksanakan. Salah satu aspek untuk menentukan kelayakan usaha salah satunya adalah aspek finansial.

R/C Ratio menurut Suratiyah (2005) (dalam Asnidar \& Asrida, 2017) merupakan perhitungan perbandingan antara total penerimaan dengan total biaya.

NPV (Net Present Value) merupakan metode penilaian kelayakan usaha yang dapat membuat arus kas dibandingkan biaya peluang dari capital yang ditanamkan (Amsyah Hrp et al., 2019). Menurut Husain (2003) dalam (Susilowati \& 
Kurniati, 2018) penilaian pada suatu usaha jika NPV $>0$ maka dapat dikatakan layak. Berikut rumus perhitungan NPV:

$$
N P V=\sum_{i=1}^{n} N B_{i}(1+1)^{-n}
$$

NB menunjukkan Net Benefit dimana benefit dikurangi cost, i menunjukkan diskon faktor dan n menunjukkan waktu.

Menurut Soetriono (2006) dalam (Kusmiati \& Nursamsiyah, 2015) Internal Rate of Return (IRR) merupakan metode untuk menganalisis tingkat suku bunga, dengan formulasi penilaian sebagai berikut:

$$
\mathrm{IRR}=\mathrm{i}_{1}+\frac{\mathrm{NPV} 1}{(\mathrm{NPV} 1-\mathrm{NPV} 2)} \times\left(\mathrm{i}_{2}-\mathrm{i}_{1}\right)
$$

Dimana i1 merupakan tingkat suku bunga yang menghasilkan NPV 1 sedangkan i2 merupakan tingkat suku bunga yang menghasilkan NPV 2.

Net B/C merupakan metode untuk menganalisis perbandingan antara jumlah keuntungan dengan jumlah biaya. Secara sistematis, berikut perhitungannya:

$$
N e t \mathrm{~B} / \mathrm{C}=\frac{\sum_{i=1}^{n} N B(+)}{\sum_{i=1}^{n} N B(-)}
$$

Dengan hasil analisis $B / C>1$ maka usaha dapat diteruskan, sedangkan $\mathrm{B} / \mathrm{C}<1$ usaha tidak dapat diteruskan.

Dari uraian latar belakang diatas dapat ditarik rumusan masalah dari penelitian ini: (1) Berapa besar tingkat pendapatan usaha Batik di Batik New Collet Desa Jati Pelem Kecamatan Diwek Kabupaten Jombang? (2) Bagaimana tingkat kelayakan usaha Batik di Batik New Collet Desa Jati Pelem Kecamatan Diwek Kabupaten Jombang jika ditinjau dari Net Present Value (NPV), Internal Net of Return (IRR), Benefit Cost Ratio (B/C) dan R/C Ratio?

Tujuan; (1) Untuk mengetahui berapa besar tingkat pendapatan usaha Batik di Batik New Collet Desa Jati Pelem Kecamatan Diwek Kabupaten Jombang? (2) Untuk mengetahui tingkat kelayakan usaha Batik di Batik New Collet Desa Jati Pelem Kecamatan Diwek Kabupaten Jombang jika ditinjau dari Net Present Value (NPV), Internal Net of Return (IRR), Benefit Cost Ratio (B/C) dan R/C Ratio?

\section{METODE}

Tabel 1. Depresiasi /Penyusutan

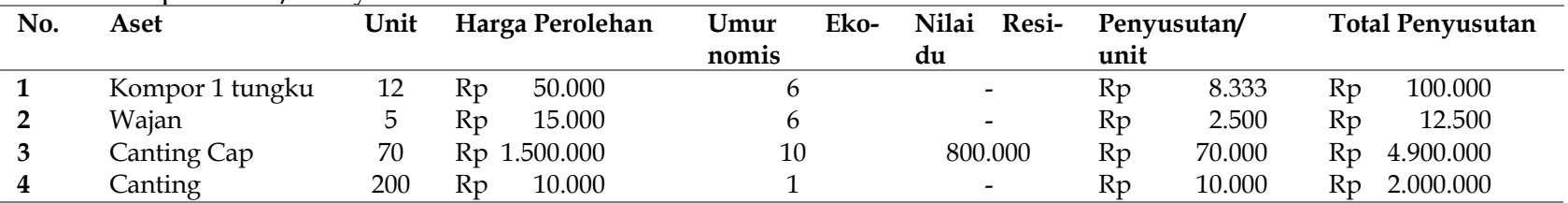

Jenis penelitian ini adalah penelitian Kuantitatif purposive. Menurut (Sugiyono, 2017) Penelitian Kuantitatif merupakan penelitian yang menggunakan filsafat Positivisme, dimana penelitian ini memandang relitas yang relative tetap, dan terukur dan juga memiliki hubungan gejala bersifat sebab akibat. Dan sedangkan purposive merupakan tehnik penentuan sampel dengan pertimbangan tertentu (Sugiyono, 2017)

Penelitian ini bersifat menguji, dimana peneliti mencoba untuk melakukan penelitian yang ilmiah dan systematis, dengan menguraikan faktafakta hasil penelitian yang datanya berupa angka hasil perhitungan.

Objek penelitian ini adalah Batik New Collet yang berada di Dusun Jaten Desa Jatipelem Kecamatan Diwek Kabupaten Jombang.

Metode pengumpulan data dalam penelitian ini adalah penelitian lapangan dan penelitian keputakaan, dimana penelitian lapangan ini dilakukan dengan cara interview, dokumentasi dan observasi.

\section{HASIL DAN PEMBAHASAN}

Penelitian kelayakan usaha ini akan menguji R/C Ratio, Net Present Value, Internal Rate of Return dan Net B/C sebagai penilaian kelayakan usaha (Qomariyah, 2019).

Penerimaan adalah perhitungan jumlah produksi dikalikan dengan harga yang dinilai dalam satuan rupiah (Septiawan, Dini Rochdiani, 2017). Penerimaan yang dihasilkan oleh Batik New Collet merupakan hasil dari jumlah kain batik yang diproduksi (kuantitas) dikalian dengan harga jual. Diperoleh pada tahun 2016 penerimaan yang diterima Batik New Collet sebesar Rp. 100.849.000, pada tahun 2017 diperoleh penerimaan sebesar Rp. 280.322.000, selanjutnya pada tahun 2018 diperoleh penerimaan Rp. 260.500.000, ditahun 2019 penerimaan usaha diperoleh Rp. 349.765.000 Dan yang terakhir pada tahun 2020 diperoleh penerimaan senilai Rp. 550.567.000. Penerimaan yang diperoleh Batik New Collet pada tahun 2016 hingga tahun 2020 mengalami kenaikan disetiap tahunnya. Diketahui bahawa pada tahun 2020 wabah covid - 19 masuk di Indonesia, hal ini tidak berpengaruh dalam penjualan karena penjualan Batik terbantu oleh penjualan online. 
Studi Kelayakan Bisnis Usaha Batik Dengan Metode Finansial Siti Nur Qomariyah, Candra Fatmawati Firdaus

\begin{tabular}{|c|c|c|c|c|c|c|c|c|c|}
\hline 5 & Ember & 6 & 30.000 & 1 & - & $\mathrm{Rp}$ & 30.000 & $\mathrm{Rp}$ & 180.000 \\
\hline 6 & Мeja Сap & 1 & 800.000 & 5 & - & $\mathrm{Rp}$ & 160.000 & $\mathrm{Rp}$ & 160.000 \\
\hline 7 & Meja Colet & 5 & 200.000 & 5 & - & $\mathrm{Rp}$ & 40.000 & $\mathrm{Rp}$ & 200.000 \\
\hline 8 & Jemuran & 10 & 30.000 & 2 & - & $\mathrm{Rp}$ & 15.000 & $\mathrm{Rp}$ & 150.000 \\
\hline 9 & Pengeringan & 1 & Rp 50.000.000 & 20 & - & $\mathrm{Rp}$ & 2.500 .000 & $\mathrm{Rp}$ & 2.500 .000 \\
\hline 10 & Water Glass Tools & 1 & $\operatorname{Rp} 20.000 .000$ & 15 & - & $\mathrm{Rp}$ & 1.333 .333 & $\mathrm{Rp}$ & 1.333 .333 \\
\hline 11 & Panci Melorot & 2 & Rp $\quad 400.000$ & 5 & - & $\mathrm{Rp}$ & 80.000 & $\mathrm{Rp}$ & 160.000 \\
\hline & \multicolumn{7}{|c|}{ Total } & \multicolumn{2}{|c|}{ Rp 11.695.833 } \\
\hline
\end{tabular}

Sumber: Data primer diolah (2021)

Tabel 1 merupakan perhitungan penyusutan aset. Diketahui penyusutan atas asset yang dimiliki oleh Batik New Collet setiap tahunnya Rp. 11.695.833. Nilai penyusutan didapatkan dari unit asset dikali dengan harga perolehan dan dibagi oleh umur asset jika digunakan secara kontinu.

Tabel 2. Biaya produksi Batik New Collet

\begin{tabular}{|c|c|c|c|c|c|c|}
\hline \multirow[t]{3}{*}{ Tahun } & \multicolumn{5}{|c|}{ Biaya } & \multirow[t]{3}{*}{ Total Biaya } \\
\hline & \multicolumn{2}{|c|}{ Fix Cost } & \multicolumn{3}{|c|}{ Variabel Cost } & \\
\hline & Sewa Tempat & Depresiasi & Biaya Air & Transportasi & Gaji Keryawan & \\
\hline 2016 & Rp 3.500.000 & Rp 11.695.833 & Rp $\quad 900.000$ & $\begin{array}{ll}\mathrm{Rp} & 50.000\end{array}$ & $\operatorname{Rp} 38.729 .000$ & Rp 54.874 .833 \\
\hline 2017 & Rp 3.500.000 & Rp 11.695.833 & 900.000 & Rp $\quad 200.000$ & Rp $\quad 69.268 .000$ & Rp 85.563 .833 \\
\hline 2018 & Rp 3.500.000 & Rp 11.695.833 & Rp. 1.000 .000 & Rp 400.000 & Rp 55.430 .500 & Rp 72.026 .333 \\
\hline 2019 & Rp 3.500.000 & Rp 11.695.833 & Rp 1.200 .000 & Rp 1.298.500 & $\operatorname{Rp} 58.671 .000$ & Rp 76.365 .333 \\
\hline 2020 & Rp 3.500.000 & Rp 11.695.833 & Rp 1.500.000 & Rp 2.266.000 & $\operatorname{Rp} 81.998 .000$ & Rp 100.959.833 \\
\hline
\end{tabular}

Sumber: Data primer diolah (2021)

Berdasarkan tabel 2. Jumlah total biaya yang dikeluarkan Batik New Collet selalu mengalami penambaham biaya setiap tahunnya, pada tahun 2016 biaya yang dikeluarkan Rp. 54.874.833, tahun 2017 naik menjadi rp. 85.563.833, tahun 2018 naik menjadi Rp. 72.026.333, tahun 2019 naik menjadi Rp. 76.365 .333 dan tahun 2020 naik menjadi Rp. 100.959.833. Jadi selama 5 tahun terakhir total biaya yang dikeluarkan adalah Rp. 352.556.835,-.

Revenue Cost Ratio merupakan perhitungan anatara total penerimaan dibagi dengan total biaya, untuk memeperoleh keuntungan pada Batik New Collet (Asnidar \& Asrida, 2017). Dikuatkan dengan pendapat dari (Syaifudin \& Qomariyah, 2021) yaitu perbandingan tingkat pendapatan yang diperoleh pada Batik New Collet dengan modal (biaya) yang dikeluarkan saat memproduksi.

Berdasarkan hasil analisis tabel 3, nilai R/C Ratio pada Batik New Collet pada 5 tahun terakhir tahun 2016-2020 adalah 4,07. Perhitungan ini akan sesuai dengan kriteria apabila nilai $\mathrm{R} / \mathrm{C}$ ratio $>1$ maka
Dalam proses produksi batik, ada biaya yang dikeluarkan. Menurut (Irmawati et al., 2018) biaya adalah semua pengeluaran yang dikeluarkan saat produksi baik itu biaya variabel maupun biaya tetap. usaha tersebut layak untuk dikembangkan. Tabel 3. Perhitungan Revenue Cost Ratio

\begin{tabular}{cccc}
\hline Tahun & Penerimaan & \multicolumn{2}{c}{ Total Biaya } \\
\hline 2016 & Rp 100.849.000 & Rp 54.874 .833 \\
2017 & Rp 280.322.000 & Rp 85.563 .833 \\
2018 & Rp 260.500.000 & Rp 72.026 .333 \\
2019 & Rp 394.765.000 & Rp 76.365.333 \\
2020 & Rp 550.567.000 & Rp 100.959.833 \\
\hline Total & Rp1.587.003.000 & Rp389.790.165 \\
\hline & R/C & $\mathbf{4 , 0 7 1 4 2 9 0 4 7}$ \\
\hline
\end{tabular}

Sumber : Data primer diolah (2021)

Net Present Value (NPV) merupakan metode untuk menghitung antara penerimaan kas dengan suku bunga bank (Pratiwi et al., 2020). Penelitian ini mengasumsikan $10 \%$ sebagai besarnya suku bunga.

Tabel 4. Perhitungan Net Present Value (NPV)

\begin{tabular}{ccccccc}
\hline Tahun & Penerimaan & Total Biaya & Pendapatan & Df 10\% & Pv Kas Bersih \\
\hline 2016 & Rp. 100.849.000 & Rp 54.874.833 & Rp 45.974 .167 & 0,909 & $\operatorname{Rp} 41.790 .518$ \\
2017 & Rp. 280.322.000 & Rp 85.563.833 & Rp 194.758.167 & 0,826 & $\operatorname{Rp~160.870.246~}$
\end{tabular}


Jurnal Studi Manajemen dan Bisnis

Vol. 8 (1) 2021: 11-16

\begin{tabular}{|c|c|c|c|c|c|}
\hline 2018 & Rp. 260.500 .000 & Rp 72.026 .333 & Rp 188.473.667 & 0,751 & $\operatorname{Rp} 141.543 .724$ \\
\hline 2019 & Rp. 349.765 .000 & Rp 76.365.333 & Rp 273.399.667 & 0,683 & Rp 186.731 .973 \\
\hline 2020 & Rp. 550.567.000 & Rp 100.959.833 & Rp 449.607.167 & 0,621 & Rp 279.206.051 \\
\hline
\end{tabular}

Sumber : Data primer diolah (2021)

Pada penelitian ini tingkat suku bunga diasumsikan dengan menggunakan nilai 10\% setiap tahunnya selama lima tahun, karena suku bunga pinjaman saat itu antara 9-11\%. Berdasarkan tabel 4, nilai NPV setiap tahun tidak kurang dari 0 artinya usaha batik new colet feasible untuk dilanjutkan. Pada tahun 2016 diperoleh PV kas bersih Rp. 41.790.518, pada tahun 2017 diperoleh PV kas

bersih sebesar Rp. 160.870.246, pada tahun 2018 diperoleh PV kas bersih Rp. 141.543.724, pada tahun 2019 diperoleh PV kas bersih Rp. 186.731.973 dan pada tahun 2020 diperoleh PV kas bersih Rp. 279.206.051. Dengan jumlah PV kas bersih selama 5 tahun terakhir adalah Rp. 913.104.722.

Internal rate of return merupakan metode yang digunakan untuk menghitung pengembalian biaya dengan meningkatkan tingkat suku bunga maksimum (Khotimah \& Sutiono, 2015).

Tabel 5. Perhitungan internal rate of return

\begin{tabular}{|c|c|c|c|c|c|}
\hline Tahun & Net Benefit & Df $10 \%$ & Pv Kas Bersih & DF $12 \%$ & Present Value \\
\hline 2016 & $\operatorname{Rp} 45.974 .167$ & 0,909 & $\operatorname{Rp} 41.790 .518$ & 0,893 & Rp37.318.933 \\
\hline 2017 & Rp 194.758.167 & 0,826 & Rp 160.870.246 & 0,797 & Rp128.213.586 \\
\hline 2018 & Rp 188.473.667 & 0,751 & Rp 141.543.724 & 0,712 & Rp100.779.131 \\
\hline 2019 & Rp 273.399.667 & 0,683 & Rp 186.731.973 & 0,636 & Rp118.761.535 \\
\hline \multirow[t]{2}{*}{2020} & $\operatorname{Rp} 449.607 .167$ & 0,621 & $\operatorname{Rp} 279.206 .051$ & 0,567 & Rp158.309.831 \\
\hline & & PV1 & Rp 810.142.511 & PV2 & Rp 543.383.016 \\
\hline
\end{tabular}

Sumber: data primer diolah (2021)

Rumus untuk menentukan besarnya Internal Rate of Return adalah:

$$
\begin{aligned}
& I R R=i I+\frac{N P V^{+}}{N P V^{+}-N P V^{-}}(i 2-i 1) \\
& I R R=10+\frac{810.142 .511}{810.142 .511-543.383 .016}(12-10) \\
& I R R=10+\frac{543.383 .016}{266.759 .495}(2) \\
& I R R=14,07395445 \%
\end{aligned}
$$

Dalam penelitian ini diasumsikan 12\% karena tidak terlalu besar untuk peningkatan suku bunga. Hasil perhitungan menunjukkan, nilai IRR sebesar $14,07 \%$, nilai ini lebih besar dari tingkat suku bunga yang ditetapkan. Dengan asumsi nilai return yang berlaku di pasar (discount factor) sebesar 12\% maka dapat dikatakan bahwa usaha Batik New Collet ini memberikan keuntungan, sehingga dapat

Tabel 6. Hasil penelitian

\begin{tabular}{lll}
\hline No & Alat Analisis & Hasil Perhitungan \\
\hline 1. & Net Present Value & Rp. 913.104 .722 \\
2. & Internal Rate Of Return & $14,07 \%$ \\
3. & Net B/C & 1,80 \\
4. & R/C Ratio & 4,07 \\
\hline
\end{tabular}

Sumber : data primer diolah (2021)

Berdasarkan hasil perhitungan analisis fi- disimpulkan bahwa investasi ini layak diterima.

Net B/C merupakan perhitungan untuk menghitung nilai bersih sekarang yang dibandingkan dengan nilai sekarang bersih. Dengan ketentuan penilaian apabila nilai Net B/C Ratio $>1$, maka usaha tersebut layak untuk dilakukan dan dikembangkan. Sebaliknya.Apabila nilai Net B/C Ratio < 1, maka usaha tersebut tidak layak untuk diusahakan dan dikembangkan (Pasaribu et al., 2016) Rumus untuk menghitung Net Benefit Cost Ratio :

$$
\begin{array}{r}
\text { Net B/C }=\frac{\sum_{i=1}^{n} N B(+)}{\sum_{i=1}^{n} N B(-)} \\
\text { Net B/C }=\frac{810.142 .511}{449.607 .167} \\
=1,80188967
\end{array}
$$

Berdasarkan analisis diatas, diperoleh nilai NET B/C sebesar 1,80. Apabila nilai NET B/C lebih besar dari satu artinya usaha batik new colet layak untuk diteruskan.

$\begin{array}{ll}\text { Kriteria Penelitian } & \text { Keterangan } \\ \text { Menghasilkan nilai }(+) & \text { Layak } \\ \text { > bunga yang diisyaratkan }(10 \%) & \text { Layak } \\ \text { >dari } 1 & \text { Layak } \\ \text { >dari } 1 & \text { Layak }\end{array}$

nansial Batik New Collet desa Jati Pelem kecamatan Diwek kabupaten Jombang ini menunjukkan layak untuk diteruskan, dengan hasil net present 
value rp. 913.104.722. Internal rate of return sebesar $14,07 \%$. Net b/c sebesar 1,80 dan $\mathrm{r} / \mathrm{c}$ ratio 4,07 .

\section{SIMPULAN DAN SARAN}

Hasil penelitian kelayakan usaha pada Batik New Collet dengan asumsi penelitian 5 tahun terakhir . Nilai kelayakan usaha ditinjau dari asspek finansial dengan nilai Net Present Value sebesar Rp. 913.104.722, Internal Rate Of Return sebesar $14.07 \%$,Net B/C sebesar 1,80 dan R/C Ratio 4,07 . Hal ini meunjukan usaha batik pada tahun 2016 - 2020 layak untuk diteruskan dan dikembangkan, ditahun 2020 pandemi Covid - 19 tidak terpengaruhi karena ada penjualan Online.

\section{DAFTAR PUSTAKA}

Amsyah Hrp, M. F., Febri, S., \& Harahap, G. (2019). Analisis Kelayakan Usaha Tani Pisang Barangan (Musa acuminata L.) (Studi Kasus: Kelompok tani mekar tani Kecamatan Biru-biru). Jurnal Agriuma, 1(1). https://doi.org/10.31289/agr.v1i1.2329

Asnidar \& Asrida. (2017). Analisis Kelayakan Usaha Home Industry Kerupuk Opak Di Desa Paloh Meunasah Dayah Kecamatan Muara Satu Kabupaten Aceh Utara. Jurnal S. Pertanian, 1(1), 39-47.

Irmawati, I., Syam, H., \& Jamaluddin P, J. P. (2018). Analisis Kelayakan Finansial Dan Strategi Pengembangan Usaha Industri Rumahan Gula Semut (Palm Sugar) Dari Nira Nipah Di Kelurahan Pallantikang. Jurnal Pendidikan Teknologi Pertanian, 1(1), 76. https://doi.org/10.26858/jptp.v1i1.5147

Kasmir, \& Jakfar. (2020). Studi Kelayakan Bisnis (14th ed.). Prenadamedia Group.

Khamaludin, K., Juhara, S., \& Sodikin, S. (2019). Studi Kelayakan Bisnis Bengkel Bubut Cipta Teknik Mandiri (Studi Kasus di Perumnas Tangerang Banten). Unistek, 6(1), 1-6. https://doi.org/10.33592/ unistek.v6i1.164

Khotimah, H., \& Sutiono. (2015). Analisis Kelayakan Finansial Usaha Budidaya Bambu. Analisis Kelayakan Finansial Usaha Budidaya Bambu, 8(1), 14-24. https://doi.org/10.22146/jik.8548

Kusmiati, A., \& Nursamsiyah, D. Y. (2015). Kelayakan Finansial Usahatani Kopi Arabika dan Prospek Pengembangannya di Ketinggian Sedang. Agriekonomika, 4(2), 221-234.

Nurul, H., \& Warana, D. D. (2017). Analisis Kelayakan Finansial Pengembangan Alam Terbuka Kebumian dan Lingkuangan berkonsep Rekreasi dan Inspirasi untuk Anak di Surabaya. Prosiding Seminar Nasional Multi Ddisiplin Ilmu Dan Call For Papers Unisbank Ke3 (Sendi_U 3), 3(Sendi_U 3), 650-656.

Pasaribu, M. C., Prasmatiwi, F. E., \& Murniati, K. (2016). Analisis Kelayakan Finansial Usahatani Kakao Di Kecamatan Bulok Kabupaten Tanggamus. Jiia, 4(4), 367-375. http://sinta2.ristekdikti.go.id

Pratiwi, H., Nurmalina, R., \& Rifin, A. (2020). Studi Kelayakan Pendirian Kantor Cabang Baru PT. XYZ di Provinsi Kalimantan Timur. Jurnal Studi Manajemen Dan Bisnis, 7(2), 103113. https://doi.org/10.21107/jsmb.v7i2.9047 Qomariyah, S. N. (2019). No Title.

Septiawan, Dini Rochdiani, M. N. Y. (2017). Analisis Biaya, Penerimaan, Pendapatan Dan R/C Pada Agroindustri Gula Aren. Jurnal Ilmiah Mahasiswa Agroinfo Galuh, 4(3), 360-365.

Sobana, D. H. (2018). Studi Kelayakan Bisnis (1st ed.). Pustaka Setia.

Sugiyono. (2017). METODE PENELITIAN kuantitatif, kualitatif dan RED (25th ed.). Alfabeta.

Susilowati, E., \& Kurniati, H. (2018). Analisis Kelayakan dan Sensitivitas: Studi Kasus Industri Kecil Tempe Kopti Semanan, Kecamatan Kalideres, Jakarta Barat. BISMA (Bisnis Dan Manajemen), 10(2), 102. https://doi.org/10.26740/bisma.v10n2.p102116

Syaifudin, A., \& Qomariyah, S. N. (2021). Analisis Pendapatan Usaha Jenang Salak (Studi Kasus Ud . Halwa Indoraya Kecamatan Megaluh. 3(2), 184192. 